\title{
Development of locally-adapted faba bean cultivars for organic conditions in Germany through a participatory breeding approach
}

\section{Participatory breeding of faba bean for organic conditions}

\author{
Lamiae Ghaouti · Werner Vogt-Kaute • \\ Wolfgang Link
}

Received: 4 July 2007 / Accepted: 15 October 2007 / Published online: 30 January 2008

(C) The Author(s) 2008

\begin{abstract}
Organic farming requires cultivars that are specifically adapted to this low input cropping system. Hence, organic farmers and scientists joined in a participatory breeding approach to develop region-specific genotypes of spring faba bean for organic conditions in Germany. A set of 49 genotypes with contrasting degrees of heterozygosity and heterogeneity was used in field trials across five locations in Germany during 3 years 2004, 2005 and 2006. The material involved 18 inbred lines, their 18 polycross progenies, one blend of inbred lines, one blend of polycross progenies, one blend of hybrids and ten checks. Inbred lines are uniform, thus giving the option to be specifically adapted; whereas the polycross progenies and synthetics (Syn-1; predicted from the inbred lines and polycross progenies performance) are partly heterogeneous and heterozygous, thus giving the option to evolve. Agronomic performance was assessed and a "personal appreciation" score of the material was assigned to each
\end{abstract}

L. Ghaouti · W. Link ( $₫)$

Department of Crop Sciences, Georg-August University,

Von Siebold-Str. 8, 37075 Göttingen, Germany

e-mail: wlink@gwdg.de

L. Ghaouti

e-mail: lamiaeghaouti@hotmail.com

W. Vogt-Kaute

Naturland-Verband für naturgemäßen Landbau e.V., Kleinhadernerweg 1, 82166 Gräfelfing, Germany

e-mail:w.vogt-kaute@naturland.de genotype by each partner. This personal appreciation was strongly influenced by biotic and abiotic constraints faced by the crop in each location and by the expected grain yield of the genotypes. Uniformity was apparently appreciated by organic farmers. In all locations, the highest yielding inbred line yielded slightly better than the predicted highest yielding synthetic. However, this slight disadvantage of the synthetic is very likely to disappear if the synthetic (Syn-1) is propagated during successive generations.

Keywords Faba bean - Inbred lines .

Local breeding . Organic farming .

Participatory plant breeding - Synthetic cultivars

$\begin{array}{ll}\text { Abbreviations } \\ \text { CK } & \text { Checks } \\ \text { GLA } & \text { German Land Appraisal } \\ \text { HB } & \text { Hybrid blend } \\ \text { IL } & \text { Inbred line } \\ \text { LB } & \text { Inbred lines blend } \\ \text { PP } & \text { Polycross progenies } \\ \text { PB } & \text { Polycross progeny blend }\end{array}$

\section{Introduction}

Organic farming is increasingly gaining interest in Europe. In Germany, organic agricultural area occupied $2.3 \%$ of the total agricultural area in 1998 and reached 
$4.8 \%$ in 2002. For comparison, the share of organic farming area in total agricultural area was $1.7 \%$ in France and $8.7 \%$ in Austria in 2002 (Eurostat 2002).

According to EU Regulation 2092/91 modified in 2005 , organic production refrains from using agrochemical inputs such as mineral fertilizers, pesticides and herbicides. Consequently, diseases, weeds and availability of nitrogen are often major constraints for an adequate productivity in organic farming.

The major crops grown in the organic farming system in Germany are cereals; they occupied $23 \%$ of the organic acreage in 2004. Faba bean (Vicia faba L.) as a grain legume crop has a considerable potential and fits well to the organic requirements. It produces its own nitrogen supply in addition to supplying a nitrogen reserve for the following crops in the rotation. Faba bean was found to have the highest amount of total nitrogen residues among legume crops reaching $100 \mathrm{~kg} / \mathrm{ha}$ (Kaul et al. 1996). Faba bean can serve as break for cereal rotation systems, decreasing diseases, energy costs and $\mathrm{CO}_{2}$ output. It improves additionally soil physical conditions and soil fertility (Hebblethwaite 1983). However, faba bean is one of the smallest crops in Germany. Its acreage was 16,000 hectares whereas the acreage of pea was 121,500 hectares (FAO 2005). The assets of faba bean seem to be nevertheless considered in organic farming, since compared to the other crops, this crop is rather concentrated in organic farming. In 2004, 39\% of the area devoted to faba bean was organic (ZMP 2004).

Faba bean is a partially allogamous crop with a degree of cross fertilization averaging 30-60\% (Bond and Poulsen 1983; Link 1990; Link et al. 1994b).

Due to its partial allogamy, Bond in 1982 has stated that breeding the partially heterotic and heterogeneous synthetic cultivars is more advantageous than breeding line cultivars. A synthetic cultivar is a special kind of a population cultivar. It is produced by open pollination of selected components during a limited number of generations. The number of components is restricted and the componenets are usually selected based on their per se performance and their combining ability (Becker 1988). The mixture of the components is called collectively Syn-0, and the first offspring from Syn-0 is called collectively Syn-1. Breeding synthetic cultivars was repeatedly recommended to increase yield and yield stability of faba beans (Ebmeyer
1987; Link et al. 1994a; Stelling et al. 1994a). In the past decade, superior and important faba bean cultivars like "Scirocco" and "Fuego" were population cultivars or synthetics.

In the case of faba bean, it is questionable whether the apparent superiority of synthetics over lines holds true in the organic context.

In Western Europe, organic farming relies on the improvements achieved by conventional breeding. However, the use of modern cultivars in the organic context does not imply that these are the best cultivars for the organic cropping system. Indeed, organic production is similar to marginal areas production with heterogeneous environments, large diversity of farmers' needs and lack of specifically adapted cultivars (Desclaux 2005). A major intention of organic farming is to use locally bred and adapted rather than generally adapted cultivars.

To meet the complexity of the organic farming requirements, participatory breeding involving the organic farmers themselves in the breeding process was proposed (Desclaux 2005). Anyway, with the very restricted area of organic farming the private sector is probably not investing much in regional let alone participatory and local breeding.

In addition to a specific adaptation of cultivars, organic farming principles give high priority to genetic diversity offering the possibility of local evolution. However, a contradiction exists between high genetic diversity within a cultivar and its potential to prove a specific, local adaptation. From a set of genotpypes, only one genotype can be best adapted to a given environment. This best genotype holds no or little genetic diversity and is a too small basis to realize a meaningful local evolution. If diversity is sought, inclusion of further, less welladapted genotypes into the cultivar of choice is inevitable. Thus, an increase of diversity causes a decrease in specificity of adaptation. This contradiction is true as long as genotype $\times$ environment interactions exist. Inbred lines are single genotypes, thus holding a potential to be specifically and locally adapted to the one or other environment; whereas synthetics are genetically diverse and give the possibility to locally adapt and evolve over time (Tigerstedt 1994). Faba bean inbred lines were shown to be on average lower performing than their corresponding synthetics (Stelling et al. 1994b). Nevertheless, our hypothesis is that, due to the higher 
genetic variance between inbred lines than between synthetics, the locally best adapted inbred line may outperform the locally best adapted synthetic.

The objective of this study was to combine the efforts of organic farmers, partners in an organic association and scientists in a participatory breeding approach to simultaneously study the contradiction between diversity and specificity of adaptation and to determine the most adequate type of spring faba bean cultivars fitting the requirements of a set of organic farms in Germany.

\section{Material and methods}

Breeding material and experimental design

A set of 18 inbred lines (IL) was derived from eighteen old and new European spring faba bean cultivars. They were developed via single seed descent for at least six generations. Through open pollination among these 18 inbred lines, 18 polycross progenies (PP) were produced as described by Fleck and Ruckenbauer (1989). One inbred lines blend (LB) was created by blending equal numbers of seed from each inbred line and correspondingly, a polycross progenies blend (PB) was established. From a set of 54 F1-hybrids produced from the 18 lines, a blend of F1-hybrids (HB) was constituted. The previous five entries (IL, PP, LB, PB and HB) are different regarding their genotypic structure but share a common genetic background. Furthermore, 10 checks (CK), mainly recent European spring faba bean cultivars were used. The identity of the inbred lines and the checks was described elsewhere (Ghaouti 2007). Altogether, the material consisted of 49 genotypes which were tested in five locations in Germany during 3 years (2004, 2005 and 2006). The trials were laid out as lattice design with two replicates. The plot size was $7.2 \mathrm{~m}^{2}$ with 40 seeds $/ \mathrm{m}^{2}$. The intra row spacing was $10.7 \mathrm{~cm}$ and the inter row spacing was $37.5 \mathrm{~cm}$. The trials were sown in the end of March and harvested in the end of August.

\section{The project area}

The testing sites involved four organic locations and a conventional one in Germany. Three organic locations licensed by Naturland association were organic farms, located at Tröndel $\left(54^{\circ} 20^{\prime} \mathrm{N}\right.$; $\left.10^{\circ} 30^{\prime} \mathrm{E}\right)$, Ramsthal $\left(51^{\circ} 08^{\prime} \mathrm{N} ; 10^{\circ} 04^{\prime} \mathrm{E}\right)$ and Willmering $\left(49^{\circ} 15^{\prime} \mathrm{N} ; 12^{\circ} 40^{\prime} \mathrm{E}\right)$. The remaining two locations belong to the Department of Crop Sciences: Deppoldshausen (organic nursery) and Reinshof (conventional nursery) with the coordinate $\left(51^{\circ} 31^{\prime} \mathrm{N}\right.$; $\left.09^{\circ} 55^{\prime} \mathrm{E}\right)$. Deppoldshausen is located $25 \mathrm{~km}$ North of Reinshof. In the conventional nursery Reinshof, one replicate was treated with agrochemical inputs (pesticides, insecticides and fungicides). The different geographical positions of the locations were chosen to cover a wide diversity of agroecological conditions. Tröndel is located near the coast of the Baltic Sea. It is characterized by a relatively mild climate where the temperatures are rarely below 0 degrees. It has the highest summer daylength and a high German Land Appraisal (GLA; Rust 2006; Fig. 1). The German Land Appraisal is a soil fertility index varying on a scale from 0 (minimum soil fertility) to 100 (maximum soil fertility). Reinshof and Deppoldshausen are very different for their GLA and altitude (Fig. 1). Deppoldshausen, due to its high altitude, is colder on average by one degree compared to Reinshof and has a low GLA. Ramsthal and Willmering are located in the South East of Germany. These two farms are located in relatively high altitudes and the quality of their soils is poor (Fig. 1). Willmering has the highest temperature amplitude (Table 1) which may constitute a stress for spring bean. The general pattern of precipitation was similar for all the five locations. Drought stress is rather taking place in June during flowering and the location Ramsthal was the most prone to drought stress (Fig. 2).

In the organic farms as well as in the experimental locations, the crop rotation followed was winter cereal-legume.

Participatory approach and measurements

Three organic farmers were involved in this research. Each partner (farmer or scientist) was involved in his location for the activities given below.

(a) Trial management. Farmers followed their normal management practices. For the conventional location (Reinshof), herbicides, fungicides and insecticides were used in only one replicate. 


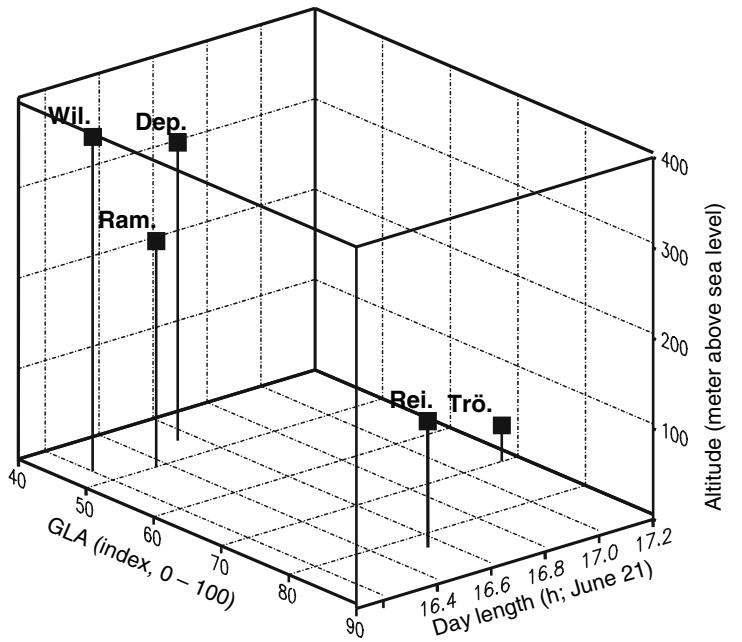

Fig. 1 Day length at 21st June, altitude and GLA (German Land Appraisal; $0=$ minimum soil fertility; $100=$ maximum soil fertility) of the five studied locations

Table 1 Mean, maximal (max), minimal (min) and average amplitude of daily temperatures across the 3 years during spring bean growing season (April-August) for each location (DWD 2006)

\begin{tabular}{lllll}
\hline Locations & \multicolumn{4}{l}{ Temperature } \\
\cline { 2 - 5 } & Mean ${ }^{\circ} \mathrm{C}$ & $\operatorname{Max}{ }^{\circ} \mathrm{C}$ & Min ${ }^{\circ} \mathrm{C}$ & Amplitude ${ }^{\circ} \mathrm{C}$ \\
\hline Tröndel & 12.4 & 16.3 & 8.4 & 7.9 \\
Deppoldshausen & 11.5 & 17.0 & 6.0 & 11.0 \\
Reinshof & 12.5 & 18.0 & 7.0 & 11.0 \\
Ramsthal & 13.1 & 18.6 & 7.5 & 11.2 \\
Willmering & 11.8 & 18.1 & 5.5 & 12.6 \\
\hline
\end{tabular}

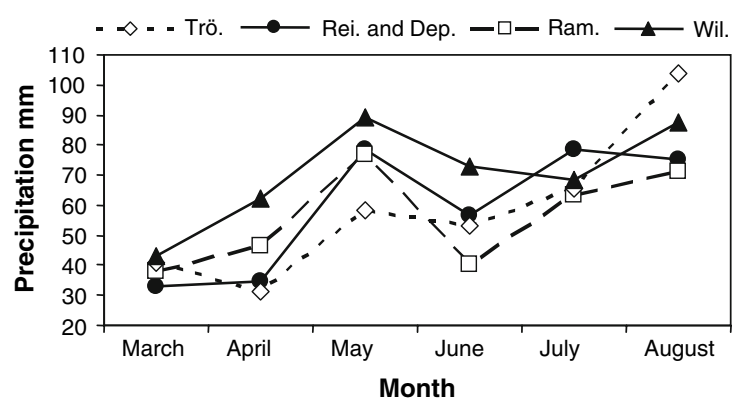

Fig. 2 Amount of precipitation in each location for each month of spring bean growing season (data are means across the 3 years 2004-2006) (DWD 2006)

(b) Scoring onset of flowering (FLW, day from January 1), plant height (HEI, cm), disease incidence scored on the basis of the visual scale reported by Bernier et al. (1984); Botrytis and/ or Aschochyta, which were the only diseases appearing in these experiments (DI, score 1-9; 1: healthy and 9: totally infested), lodging (LOD, score 1-9; 1: fully upright, $9=$ totally lodging), biomass yield (BM, 1: low biomass, 9: high biomass) and end of maturity (MAT, day from January 1).

(c) Visual estimation of yield at maturity (YE, score 1-9; 1: lowest yielding, 9: highest yielding).

(d) Personal appreciation of the material through a visual score (PA, score 1-9; 1: fully disliked, 9: fully appreciated). The development plant stage and the criteria of evaluation were chosen by each partner independently.

The scoring of YE was essential to define whether and to which extent grain yield contributes to PA.

After combine harvesting, grain yield $(\mathrm{Y}, \mathrm{t} / \mathrm{ha})$ and thousand grain weight (TGW, g) were measured and grain status (GS, score 1-9; 1: healthy grains, 9: fully infected grains) was visually estimated for each plot entry. The incidence of Aschochyta symptoms on the seeds was evaluated as grain status.

\section{Statistical analyses}

Data analysis was based on PLABSTAT (Utz 1991) as follows: First, the individual trials (one location in 1 year) were analyzed according to their lattice design. Following Cochran and Cox (1992), the resultant lattice adjusted entry means were used for (1) analyses of variance for each location across the 3 years and for (2) a combined analysis of variance across the five locations and the 3 years. A mixed model was used where the years $(\mathrm{Y})$ were random and the factors genotypes $(\mathrm{G})$ and locations (L) were fixed.

The relationship between the five genotype $\times$ location interaction (GL) effects of each genotype and the genotype's mean performance for grain yield was studied using the results of the combined analysis of variance across locations and years.

Correlations among the genotypes of the trait "personal appreciation" with the other scored traits were estimated for each location. Besides, the personal appreciation data of the locations were correlated to compare the rankings established by 
each partner. Data presented below are averaged across the 3 years. For statistical significance, *is used to indicate significance at $5 \%$ level of error probability and **at $1 \%$ level of error probability.

Prediction of the yield performance of synthetics in the first generation

In this study case, the parental components for the prospected synthetic cultivars were inbred lines. From eighteen inbred lines, $2.6 \times 10^{5}$ synthetic cultivars are possible to generate, with synthetics based on 2-18 parents. It is crucial to determine the optimum size (i.e. optimum number of components) of the synthetics and to predict their performance.

The performance of a synthetic with $\mathrm{k}$ components in the first generation Syn-1(k) is predicted as follows (Ederer and Link 1992):

$\operatorname{Syn}_{1}(k) \approx \frac{1}{k} \sum_{i=1}^{k}\left[\mathrm{~S}_{i}+\frac{k-1}{k} \frac{m}{m-1}\left(\mathrm{P}_{i}-\mathrm{S}_{i}\right)\right]$,

where $k$ is the number of components in a synthetic variety, $m$ is the number of components in the polycross ( $m=18$ in our case), $S_{i}$ is the performance of the inbred line $i$ and $\mathrm{P}_{i}$ is the performance of the polycross-progeny of the inbred line $i$. This prediction is based on assumptions as described by Link and Ederer (1992) and Link and Ederer (1993).

Based on the yield performance of the inbred lines and their polycross progenies, the highest performing synthetics in generation Syn-1 were predicted for each location, and compared to the highest yielding inbred line.

\section{Results and discussion}

Performance levels at the locations were significantly different (Table 2). Maximum yield was realized in the conventional location Reinshof. This result was expected since Reinshof has a high GLA and the plots in this location were relatively free from pests, diseases and weeds. Yield performance in the treated replicate and in the non treated replicate was not significantly different. Symptoms of two foliar diseases were detected in the five locations: Ascochyta fabae and Botrytis fabae, and one seed disease, Ascochyta fabae. The score of disease incidence reflected the joint foliar incidence of Botrytis and Aschochyta whereas the grain status score reflected the incidence of Aschochyta on harvested seed. Regarding the GLA and the DI, Tröndel appears to be the best organic location. Genotypes in Tröndel were higher yielding than in the three other organic locations and showed very little disease symptoms. Although the genotypes grew relatively tall, they were on average the least lodging compared to all other locations. Ramsthal was characterized by a low GLA, highest disease incidence and drought stress during flowering time. Genotypes in Ramsthal were on average early flowering with the smallest height due to the drought, and thus achieving the lowest yield. Willmering was the latest flowering and the earliest maturing location. The duration of flowering and the pod filling period were the shortest in this location; this may have contributed to the low yield observed. The highest lodging scores were recorded in Willmering. The plots in Deppoldshausen were the latest maturing.

The difference between the genotypes was highly significant for grain yield and flowering time (Table 3). Locations and location $x$ year interactions were the largest sources of variation for both traits. For grain yield, the variance of the genotype $\times$ environment interactions $(\mathrm{GL}+\mathrm{GY}+\mathrm{GYL})$ was larger than the genotypic variance. Genotype $\times$ location interactions were the strongest components of the joint genotype $\times$ environment interactions and contributed more than half as much as the genotypes to the yield variation. Urgent need to improve yield stability of faba bean in conventional farming is well-known (e.g., Dantuma et al. 1983; Bond et al. 1993). In the organic context yield instability is supposed to be even larger since $\mathrm{G} \times \mathrm{E}$ is not buffered by agrochemical inputs. Large genotype $\times$ environment interactions for grain yield in low input environments were observed in other crops such as barley (Ceccarelli et al. 2003) and rice (Courtois et al. 2001). Here, for all other agronomic traits, all sources of variations were as well significant and genotype $\times$ location interactions were as well the largest component of the genotype $\times$ environment interactions (details not shown).

The location Tröndel was taken as an example to illustrate the pattern of the genotypes' grain yield distribution (Fig. 3). The genotypes distribution was distinct according to the genotypic structure. Inbred lines performed less than the polycross progenies in Tröndel as well as on average across locations. It never occurred that, in Tröndel or in any single 
Table 2 Mean values across 3 years of the relevant agronomic traits of a set of 49 faba bean genotypes in Germany

\begin{tabular}{lllllllll}
\hline Locations & FLW day & HEI cm & LOD score & MAT day & DI score & GS score & TGW g & Y t/ha \\
\hline Tröndel & 167 & 116 & 1.50 & 223 & 2.10 & 3.69 & 495 & 3.54 \\
Deppoldshausen & 164 & 104 & 2.31 & 238 & 3.39 & 3.34 & 517 & 3.40 \\
Reinshof & 161 & 123 & 3.07 & 228 & 1.63 & 2.23 & 469 & 4.62 \\
Ramsthal & 158 & 89 & 2.90 & 223 & 5.71 & 5.08 & 455 & 2.39 \\
Willmering & 178 & 101 & 3.82 & 216 & 4.24 & 5.45 & 540 & 2.96 \\
Average & 165 & 107 & 2.72 & 226 & 3.61 & 3.76 & 495 & 3.38 \\
LSD 5\% & $9 *$ & $42 *$ & $1.10^{*}$ & $19 *$ & $3.51 *$ & $2.28 *$ & $77 *$ & $1.61 *$ \\
\hline
\end{tabular}

FLW (onset of flowering), HEI (height), LOD (lodging, score 1-9; 1: fully upright, 9 = totally lodging), MAT (end of maturity), DI (Disease incidence; Aschochyta and/or Botrytis, score 1-9; 1: healthy and 9: totally infected), GS (grains status; Aschochyta symptoms on the seeds, score 1-9; 1: healthy, 9: fully infected), TGW (thousand grain weight) and Y (grain yield)

Table 3 Combined analysis of variance including variance components $\left(\sigma^{2}\right)$ of grain yield and flowering time across genotypes, years and locations

\begin{tabular}{|c|c|c|c|c|c|c|c|c|}
\hline \multirow[t]{2}{*}{ Sources of variations } & \multicolumn{4}{|c|}{ Grain yield } & \multicolumn{4}{|c|}{ Flowering time } \\
\hline & $\mathrm{DF}$ & $\sigma^{2}\left(\mathrm{t}^{2} / \mathrm{ha}^{2}\right)$ & $\mathrm{F}$ value & LSD $5 \%$ & $\mathrm{DF}$ & $\sigma^{2}\left(\right.$ days $\left.^{2}\right)$ & F value & LSD $5 \%$ \\
\hline Location L & 4 & 1.09 & $5.48 *$ & 1.61 & 4 & 42.44 & $6.36^{*}$ & 9.41 \\
\hline Year Y & 2 & 0.60 & $732.86^{* *}$ & 0.08 & 2 & 13.15 & $994.19 * *$ & 0.32 \\
\hline Genotype G & 48 & 0.22 & $8.37 * *$ & 0.49 & 48 & 6.73 & $16.34 * *$ & 1.86 \\
\hline YL & 8 & 0.73 & $178.65^{* *}$ & 0.18 & 7 & 23.71 & $358.99 * *$ & 0.72 \\
\hline GL & 192 & 0.15 & $3.21 * *$ & 0.72 & 191 & 2.28 & $3.11 * *$ & 2.89 \\
\hline GY & 94 & 0.05 & $2.28 * *$ & 0.56 & 94 & 0.67 & $2.03 * *$ & 2.24 \\
\hline GYL & 373 & 0.09 & $1.90 * *$ & 0.90 & 310 & 1.80 & $2.25 * *$ & 3.34 \\
\hline Error & 517 & 0.11 & & & 441 & 1.44 & & \\
\hline
\end{tabular}

*Significance at $5 \%$ level of error probability; **significance at $1 \%$ level of error probability

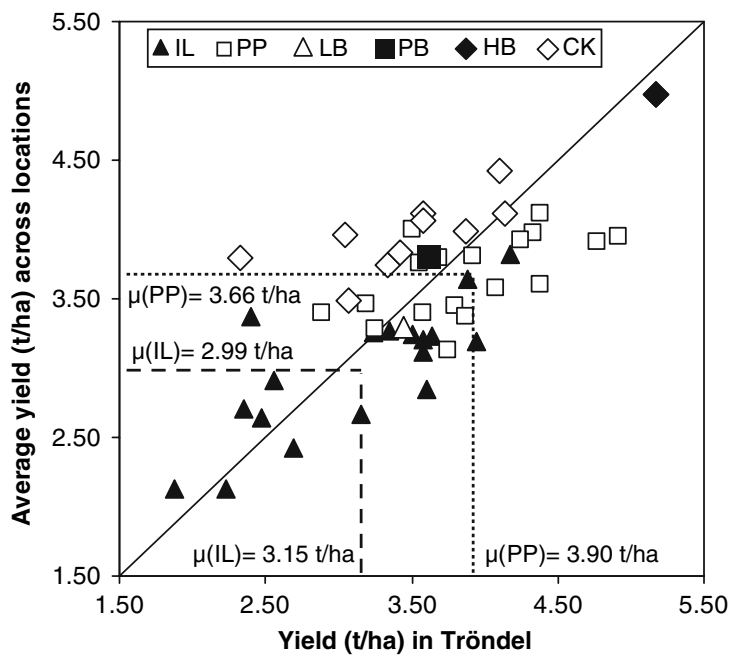

Fig. 3 Distribution of the genotypes in Tröndel and the correlation with the averages across all locations according to grain yield (means across 3 years; $t / h a)$ location, any inbred line outyielded the best polycross progeny. In Tröndel, the blend of inbred lines yielded significantly higher than the average yield of inbred lines and the blend of polycross did not yield significantly different from the average yield of polycross progenies. These findings are in concordance with general expectation (Wolfe 1985) and with previous findings for faba bean, showing that the heterogeneity at the homozygous level caused positive effects on yield (Link et al. 1994b). On average of all locations, both blends yielded higher but not significantly so than the average of their corresponding components (IL or PP). In each location and on average of all locations, the blend of hybrids was the highest yielding entry. As stated previously (Stelling et al. 1994b), the level of heterozygosity seems to be the main factor enhancing the yield performance. 
The superiority of the polycross progenies over the inbred lines for yield performance held true in each single location (Table 4). On average, the polycross progeny yielded $0.67 \mathrm{t} / \mathrm{ha}$ higher than the inbred lines which corroborated previous findings on faba bean (Link et al. 1994b; Stelling et al. 1994b). The variance among inbred lines in each location and on average of all locations was larger than the variance among the polycross progenies. In each single location and on average of all locations, yield performance of polycross progenies was positively, markedly and significantly correlated with yield of their inbred lines. On average across locations, the correlation between the inbred lines and their polycross progenies for yield performance amounted $r=0.63^{* *}$. Fleck and Ruckenbauer (1989) found as well that a significant correlation $\left(r=0.51^{* *}\right)$ existed between the inbred lines and their polycross progenies in faba bean. The inbred lines and their polycross progenies constituted as well two distinct groups according to the interaction pattern of their yield performance with the locations (Fig. 4). Interaction effects of the inbred lines with the locations were generally larger than those of the polycross progenies. For instance, the inbred line IL 12 (MarisBead/1) interacted highly with the locations; it yielded in Reinshof $0.74 \mathrm{t} / \mathrm{ha}$ more than expected from general means and $0.94 \mathrm{t} / \mathrm{ha}$ less than this in Willmering. Overall, it was the second least yielding genotype. A genotype that shows a high positive GL effect with a location is specifically adapted to this location (IL 12 seems to be specifically adapted to Reinshof), whereas a genotype with a little or zero GL effects shows a stable performance across the locations. The inbred lines tend to be more specifically adapted and specifically misadapted to single locations, whereas their polycross progenies are more stable, thus confirming our hypothesis. Heterozygous and heterogeneous

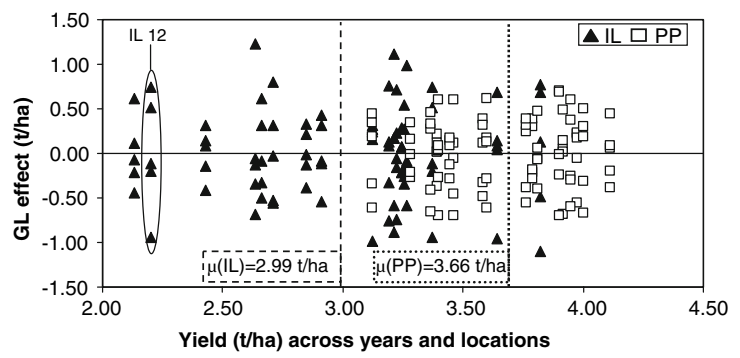

Fig. 4 Mean yield of the $18 \mathrm{IL}$ and eighteen PP (averages across years and locations; $\mathrm{x}$-axis) versus $\mathrm{G} \times \mathrm{L}$ interaction effects of these genotypes with the five locations (y-axis). Values from combined ANOVA across years and locations ( $c f$. text)

entries were found to interact less with environments than inbred lines in faba bean (Link et al. 1994a) as well as in other crops such as barley (Einfeldt et al. 2005), rapeseed (Becker and Léon 1988) and maize (Schnell and Becker 1986).

The main objective of this study was to compare two categories of cultivars in local organic conditions; inbred line cultivar and synthetic cultivar. For all locations, the optimum size of synthetics was found to be $m=4$ components. This optimum size of synthetic was the result of a compromise between reducing the inbreeding depression by increasing the number of components and increasing gain from selection by decreasing the number of components (Becker 1988; Gallais 1992). With 18 inbred lines as potential components for synthetics of size four, here 3060 possible synthetics Syn-1(4) were possible to establish.

\section{Selection based on yield performance}

The analysis of the best inbred lines in each location showed (Table 5) that the inbred line IL 1 (Maya/2) was specifically adapted to both Tröndel and
Table 4 Mean values and phenotypic variances of the 18 inbred lines and their 18 polycross progenies; and their correlations

*Significance at $5 \%$ level of error probability;

**significance at $1 \%$ level of error probability

\begin{tabular}{|c|c|c|c|c|c|}
\hline \multirow[t]{2}{*}{ Locations } & \multicolumn{2}{|c|}{ Inbred lines } & \multicolumn{2}{|c|}{ Polycross progenies } & \multirow[t]{2}{*}{$r(\mathrm{IL}, \mathrm{PP})$} \\
\hline & $\begin{array}{l}\text { Mean } \\
\text { t/ha }\end{array}$ & $\begin{array}{l}\text { Phenotypic } \\
\sigma^{2} \mathrm{t}^{2} / \mathrm{ha}^{2}\end{array}$ & $\begin{array}{l}\text { Mean } \\
\text { t/ha }\end{array}$ & $\begin{array}{l}\text { Phenotypic } \\
\sigma^{2} \mathrm{t}^{2} / \mathrm{ha}^{2}\end{array}$ & \\
\hline Tröndel & 3.15 & 0.53 & 3.90 & 0.29 & $0.55^{*}$ \\
\hline Deppoldshausen & 2.92 & 0.49 & 3.75 & 0.24 & $0.57 *$ \\
\hline Reinshof & 4.08 & 0.32 & 4.97 & 0.21 & $0.73 * *$ \\
\hline Ramthal & 2.22 & 0.39 & 2.48 & 0.32 & $0.57 *$ \\
\hline Willmering & 2.58 & 0.46 & 3.21 & 0.22 & $0.71 * *$ \\
\hline Average & 2.99 & 0.44 & 3.66 & 0.26 & $0.63 * *$ \\
\hline
\end{tabular}


Ramsthal. The three other locations had each a different specifically adapted inbred line, IL 4 (Styria 343), IL 10 (L1_MxCEx/19) and IL 14 (Music/1). In each location, the best inbred line was one of the four components of the best Syn-1(4). This result is expected since the yield performance of the inbred lines was positively correlated to the yield performance of their corresponding polycross progenies and thus to their contribution to the best synthetic cultivar. The best synthetics among the locations were established from 12 different components out of the available 18. The best synthetics covered a large diversity of the available components confirming that the locations had indeed different environments. In each location, the synthetics were predicted to yield on average higher than the inbred lines which is in concordance with the theoretical expectations established by Gallais (1992). This superiority is mainly due to the partial heterosis expressed in the synthetics. However, the comparison between the actually highest yielding inbred line and the predicted to be highest yielding Syn-1(4) as identified in each location turned out in favor of the inbred line in each location. Again in each location, the highest yielding inbred line and the highest yielding synthetic were higher yielding than the highest yielding check entry, albeit nowhere significantly so. Nevertheless, taking averages across locations, the highest yielding check (Bilbo) significantly outyielded the highest yielding inbred line (Maya/2; details not shown). Checks were released cultivars derived from formal breeding. Apparently such cultivars are not necessarily best adapted to single locations, but showed up as superior when ranking is based on means across a range of locations.

A cross validation test was performed to verify (1) whether the best inbred line is indeed best in a given location, (2) whether the best Syn-1(4) is indeed best in a given location and (3) whether the best inbred line is indeed outyielding the best synthetic in a given location. The data of each of the 3 years in a given location were partitioned into two subsets; calibration set (mean across 2 years) and validation set (the residual third year).

(1) Initially, the highest yielding inbred line from the mean of 2 years data was identified and the third year was retained to test whether the predicted best inbred line was indeed best in the third year.
Three validation sets were available in each location and 15 validation sets were available among all five locations. The best inbred line predicted from the calibration set was accepted as indeed "best" if in the validation test, it was the highest or second highest yielding, i.e. based on a ratio of two out of $18(11.11 \%)$. The result of this analysis revealed that in 10 out of 15 cases (67\%), the predicted to be best inbred line from the calibration set was best or second best in the validation set.

(2) The same analysis was done for the best Syn1(4) but for the validation, the best Syn-1(4) predicted from the calibration set was considered to be indeed "best" if it ranked in the validation set among the 340 highest yielding Syn-1(4) out of 3,060. This represents the same ratio as for the inbred lines $(11.11 \%)$. The result showed that the predicted to be best Syn-1(4) was always "best" in the validation set. A second, stricter validation threshold 80/3,060 $(2.61 \%)$ gave a similar result as the result of the validation test of the best inbred lines with $11.11 \%$ threshold: in 10 cases out of 15 , the predicted to be best Syn-1(4) was ranked among the 80 best in the validation set.

(3) In each location, the highest yielding inbred line and the highest yielding Syn-1(4) from the mean of each 2 years data were identified and their performance was checked and compared in the residual third year. In 10 cases out of 15 , the predicted to be best inbred line yielded higher than the predicted to be best Syn-1(4). The average difference across all 15 cases was about $3 \%$ in favor of the inbred lines.

Cross validation data confirmed our results since, (1) in most cases the best inbred line and the best synthetic could be well enough predicted and since (2) it is more likely that the best inbred line outyields the best synthetic than the opposite.

It is worthwhile to stress that the apparent superiority in yield performance of the locally best inbred line over the locally best synthetic was not marked. Furthermore, it must be stressed that the synthetics were predicted for the generation Syn-1. The panmictic index and thus yield of a synthetic is expected to increase with further generation of propagation (Busbice 1969; Link 1990). Stelling 
Table 5 Average yield performance of the inbred lines and the synthetics Syn-1(4), and yield performance and identity of the best inbred line and the best Syn-1(4) in each location

\begin{tabular}{|c|c|c|c|c|c|c|}
\hline Locations & $\begin{array}{l}\text { Average } \\
\text { Y of } 18 \mathrm{IL} \\
(\mathrm{t} / \mathrm{ha})\end{array}$ & $\begin{array}{l}\text { Average Y } \\
\text { of } 3060 \text { Syn-1(4) }\end{array}$ & $\mathrm{Y}$ of the best IL & $\begin{array}{l}Y \text { of the } \\
\text { best Syn-1(4) }\end{array}$ & $\begin{array}{l}\text { Idendity of } \\
\text { best IL }\end{array}$ & $\begin{array}{l}\text { Idendity of best } \\
\text { Syn-1(4) components }\end{array}$ \\
\hline Tröndel & 3.15 & 3.74 & 4.78 & 4.47 & 1 & $1 ; 18 ; 15 ; 17$ \\
\hline Deppoldshausen & 2.92 & 3.58 & 4.27 & 4.19 & 4 & $18 ; 4 ; 10 ; 6$ \\
\hline Reinshof & 4.08 & 4.79 & 5.42 & 5.39 & 10 & $10 ; 11 ; 3 ; 4$ \\
\hline Ramsthal & 2.22 & 2.43 & 3.50 & 3.07 & 1 & $1 ; 6 ; 5 ; 10$ \\
\hline Willmering & 2.58 & 3.08 & 3.91 & 3.73 & 14 & $14 ; 1 ; 3 ; 7$ \\
\hline
\end{tabular}

et al. (1994b) observed in faba bean a yield increase from the first to the second generation of synthetics of $1-8 \%$. This expected heterotic increase of yield of the best synthetic in the second generation may cancel the small advantage of the highest yielding inbred line.

Moreover, as shown above, the prediction of the synthetics' performance is more reliable than the prediction of the inbred lines' performance. Therefore, in spite of the finding that the locally highest yielding line tended to be superior over the locally best synthetic, this finding was only corroborated in $75 \%$ of the cases by cross validation. Besides, in the long term the synthetics have a great local advantage through their genetic heterogeneity which is their genetic adaptability.

\section{Selection based on farmers criteria}

The visual estimation of yield in the field by each partner (farmer or scientist) was highly correlated to the realized grain yield after harvesting. The correlation between visually estimated yield and realized yield ranked from $0.44 * *$ to $0.70^{* *}$ in the five single locations and amounted on average to $r=0.60^{* *}$.
Farmers were more or less successful in identifying the highest yielding genotypes.

All partners based their appreciation of the genotypes to a large extent on their score of visual estimation of yield (YE, Table 6). Yield constituted for all partners an important trait. The correlation of personal appreciation and visual estimation of yield reflects the weight that each partner attributed intentionally to grain yield in his personal appreciation. For instance, the farmer in Tröndel has given a high weight to the estimated yield when assigning his personal appreciation $(r=0.84 * *)$. However, the correlation between his personal appreciation and combine harvest yield was not high in spite of been significant ( $r=0.42 * *$; Table 6 ).

Personal appreciation was strongly influenced by biotic and abiotic constraints faced by the crop in each location. As diseases were more frequent in Deppoldshausen, Ramsthal and Willmering (Table 2), higher appreciation scores were given to genotypes with little diseases symptoms and healthy seeds. In Tröndel, the correlation between personal appreciation and grain status was due to the fact that the farmer has favored genotypes that suffered less from the severe drought stress which happened in the year 2006 in this location. In the conventional

Table 6 Correlation coefficients of personal appreciation score with the agronomic traits

\begin{tabular}{lccllllllll}
\hline & FLW & HEI & LOD & MAT & DI & BM & YE & Y & GS & TGW \\
\hline Tröndel & $0.44 * *$ & $0.67 * *$ & - & $0.43 * *$ & - & - & $0.84 * *$ & $0.42 * *$ & $-0.29 *$ & $-0.37 * *$ \\
Deppoldshausen & $-0.55 * *$ & $0.38 * *$ & - & - & $-0.32 *$ & $0.61 * *$ & $0.59 * *$ & $0.52 * *$ & $-0.44 * *$ & $0.47 * *$ \\
Reinshof & $-0.51 * *$ & $-0.49 * *$ & $-0.54 * *$ & - & - & - & $0.60 * *$ & $0.48 * *$ & - & $0.38^{* *}$ \\
Ramthal & $0.42 * *$ & $0.79 * *$ & $-0.30^{*}$ & $0.32 *$ & $-0.35 *$ & $0.71 * *$ & $0.68 * *$ & $0.49 * *$ & $-0.53 * *$ & $-0.29 *$ \\
Willmering & - & $0.39 * *$ & - & - & $-0.34 *$ & $0.34 *$ & $0.66 * *$ & $0.36 *$ & $-0.42 * *$ & $-0.37 * *$ \\
\hline
\end{tabular}

*Significance at $5 \%$ level of error probability; **significance at $1 \%$ level of error probability; - non significant coefficient of correlation 
location Reinshof, short genotypes were favored due to the high lodging pressure in this location. Tall genotypes were favored by all partners in organic locations. The scoring decisions of the farmer in Ramsthal resulted from a compromise between tall and less lodging genotypes. Early flowering and maturing material was favored in Reinshof and Deppoldshausen and late flowering and maturing material was favored in Tröndel and Ramsthal. In the organic locations Deppoldshausen, Ramsthal and Willmering, genotypes with high biomass were most appreciated apparently because they outcompeted weeds. The incidence of weeds was very low in Tröndel and absent in Reinshof due to the weed management (herbicides or manual weeding). Farmers favored small seeded genotypes whereas in Deppoldshausen and Reinshof, big seeded genotypes were the most appreciated. This maybe due to the high yield of big seeded types recorded only in Reinshof and Deppoldshausen. The selection criteria used by farmers were neither unusual nor unexpected. They translated mainly their requirements according to their agro-ecological conditions. This result corroborated the findings of other participatory researches (Ceccarelli et al. 2000). Correlations of the scores of personal appreciation in each location showed that the scores in both Deppoldshausen and Reinshof were significantly and positively correlated $\left(r=0.46^{* *}\right)$ which is apparently due to the scoring achieved by the same partner in both locations. The scores of personal appreciation in Reinshof were significantly and negatively correlated to the ones in Tröndel $(r=-$ $\left.0.48^{* *}\right)$. In the other cases, the scores of personal appreciation were independent. This independency reflects partly genuine differences between farmers' appreciations and partly the large interaction between genotypes and location, the latter being the basic motivation for local and participatory breeding.

Admittedly, strictly local breeding may not be economically feasible. However, a combination of regional and participatory breeding should be analysed further. The large genotype $\times$ location interactions contributed to the development of several regional breeding programs such the development of regional breeding programs for wheat in Australia (Bänziger and Cooper 2001).

Eighteen superior genotypes out of $N=49$ were identified in each location according to yield performance in a first instance, and to the personal appreciation scores in a second instance. The contribution of the different genotypic structure to the superior genotypes was assessed. In all locations, the 18 superior genotypes according to yield performance and to personal appreciation scores included the hybrids blend entry. Inbred lines blend and the polycross progenies blend never ranked among these superior genotypes. Checks contributed similarly to the highest yielding (23\%) and to the most appreciated genotypes $(28 \%)$. A high discrepancy between the selection based on yield performance or personal appreciation was mainly occurring for the contribution of the inbred lines and the polycross progenies (Figs. 5 and 6).

On average, the total contribution of the inbred lines and their polycross progenies amounted to $71 \%$ of the highest yielding genotypes and to $66 \%$ to the most appreciated genotypes. On average of the locations, the inbred lines contributed with $18 \%$ to the highest yielding genotypes whereas the polycross progenies contributed with $53 \%$. The contribution of the inbred lines increased markedly when considering the personal appreciation (Fig. 6). In each single location as well as on average, inbred lines were more frequently present among the most appreciated

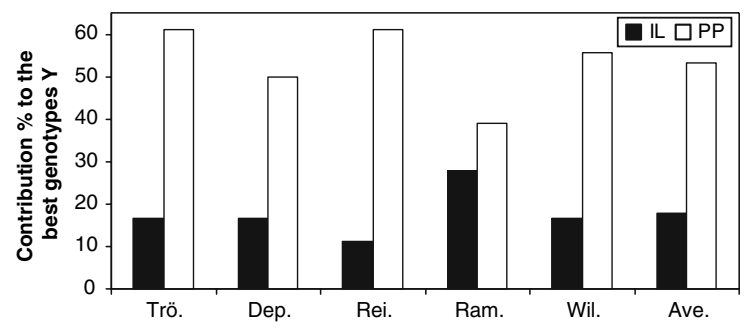

Fig. 5 Contribution in $\%$ of the inbred lines and their polycross progenies to the 18 superior genotypes according to the yield performance (Y)

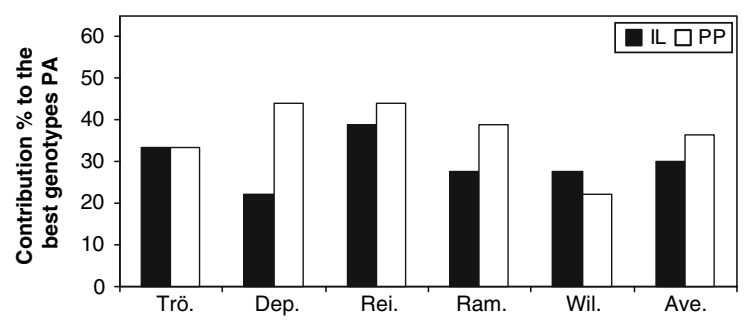

Fig. 6 Contribution in $\%$ of the inbred lines and their polycross progenies to the 18 superior genotypes according to the personal appreciation (PA) 
genotypes than among the highest yielding genotypes. In each location, the highest yielding inbred line ranked among the most appreciated genotypes. Organic farmers apparently did not disfavor homogeneity. Compared to the yield selection, farmers increased the contribution of the (homogeneous) inbred lines and decreased the contribution of the (heterogeneous) polycross progenies to the most appreciated genotypes. Uniformity was apparently appreciated by organic farmers and heterozygous and heterogeneous material seemed to be appreciated not due to its genotypic structure but due to its visible high yield performance.

Results of this study have been obtained on farmer's field under organic and local conditions. Large genetic differences were detected that will be of immediate benefit to farmers at no additional costs. On request of the farmers, we gave them the Syn-0(4) of the best Syn1(4) according to their personal appreciation to continue the synthetic propagation and use it for their own purposes. The outcome of this study illustrated how the combined efforts of farmers and breeders in a local breeding approach led to new insight and to very suitable genotypes for organic farming.

Acknowledgements Our thanks are due to the farmers A. Hausladen (Willmering), G. Neder (Ramsthal) and H. Untiedt (Tröndel) for their very valuable contributions. Sowing and harvesting was achieved faultlessly by Agrostat Company. Finally, we thank BMELV (Bundesministeriums für Ernährung, Landwirtschaft und Verbraucherschutz) for financing this research.

Open Access This article is distributed under the terms of the Creative Commons Attribution Noncommercial License which permits any noncommercial use, distribution, and reproduction in any medium, provided the original author(s) and source are credited.

\section{References}

Bänziger M, Cooper M (2001) Breeding for low input conditions and consequences for participatory plant breeding: Examples from tropical maize and wheat. Euphytica 122:503-519

Becker H (1988) Breeding synthetic varieties of crop plants. Plant Genet Breed Rev 1:31-54

Becker HC, Léon J (1988) Stability analysis in plant breeding. Plant Breed 101:1-23

Bernier CC, Hanounik SB, Hussein MM, Mohamed HA (1984) Field manual of common faba bean diseases in the Nile Valley. ICARDA, Syria
Bond DA (1982) The development and performance of synthetic varieties of Vicia faba L. In: Hawtin G, Webb C (eds) Faba bean improvement. pp 41-51

Bond DA, Poulsen MH (1983) Pollination. In: Hebblethwaite PD (ed) The Faba Bean (Vicia faba L.). Butterworths, London, pp 77-101

Bond DA, Jellis GJ, Rowland GG, Le Guen J, Robertson LD, Khalil SA, Li-Juan L (1993) Present status and future strategy in breeding faba beans (Vicia faba L.) for resistance to biotic and abiotic stresses. Euphytica 73:151-166

Busbice TH (1969) Inbreeding in synthetic varieties. Crop Sci 9:601-604

Ceccarelli S, Grando S, Tutliwer R et al (2000) A methodological study on participatory barley breeding. I. Selection phase. Euphytica 111:91-104

Ceccarelli S, Grando S, Singh M et al (2003) A methodological study on participatory barley breeding. I. Response to selection. Euphytica 133:185-200

Cochran WG, Cox GM (1992) Experimental designs, 2nd edn. John Wiley and Sons (eds.), Inc. New York

Courtois B, Bartholome B, Chaudhary D et al (2001) Comparing farmers and breeders rankings in varietal selection for low-input environments: a case study of rainfed rice in eastern India. Euphytica 122:537-550

Dantuma G, E.von Kittlitz M Frauen DA Bond (1983) Yield, yield stability and measurements of morphological and phenological characters of faba bean (Vicia faba L.) varieties grown in a wide range of environments in Western Europe. Z Pflanzenzüchtg 90:85-105

Desclaux D (2005) Participatory plant breeding methods for organic cereals. In: Proceedings of the COST SUSVAR/ ECO-PB, Workshop on Organic Plant Breeding Strategies and the Use of Molecular Markers, Lammerts Van Bueren ET, Ostergard H (eds) pp 17-23

DWD (Deutscher Wetterdienst) (2006) http://www.dwd.de. Cited Feb 2007

Ebmeyer E (1987) Zur Bedeutung der Ertragsicherheit in der züchtung von Ackerbohnen. Vortr Pflanzenzüchtg 12:168-179

Ederer E, Link W (1992) The polycross-test as a step in breeding partially allogamous crops. Theoretical considerations. Proc. XIIIth EUCARPIA Congress, 6-11 July, Angers, France, Book of Poster Abstracts, pp 543-544

Einfeldt CHP, Ceccarelli S, Grando S et al (2005) Heterosis and mixing effect in Barley under drought stress. Plant Breed 124:350-355

Eurostat (Statistical Office of the European Communities) (2002) http://www.epp.eurostat.ec.europa.eu/portal/page? _pageid=1090,30070682,1090_30298591\&_dad=portal\&_ schema=PORTAL. Cited Feb 2007

FAO (Food and Agriculture Organization) (2005) http://www. faostat.fao.org. Cited Feb 2007

Fleck A, Ruckenbauer P (1989) Der Polycrosstest als methodischer Schritt in der Fababohnenzüchtung (experimentelle Ergebnisse). Die Bodenkultur 40:61-72

Gallais A (1992) Pourquoi faire des variétés synthétiques? Agronomie 12:601-609

Ghaouti L (2007) Comparison of pure line cultivars with synthetic cultivars in local breeding of faba bean (Vicia faba L.) for organic farming. $\mathrm{PhD}$ thesis, University of Göttingen, 
Germany. Available at http://www.resolver.sub.unigoettingen.de/purl/?webdoc-1572

Hebblethwaite PD (1983) Background, physiology and breeding. In: Hebblethwaite PD (ed) The faba bean (Vicia faba L.). Butterworths, London, pp 3-22

Kaul HP, Aufhammer W, Wägner W (1996) Dry matter and nitrogen accumulation and residues of oil and crop protein crops. Eur J Agrono 5:137-147

Link W (1990) Autofertility and rate of cross-fertilization: crucial characters for breeding synthetic varieties in faba bean (Vicia faba L.). Theor Appl Genet 79:713-717

Link W, Ederer W (1993) The concept of varietal ability for partially allogamous crops. Plant Breed 110:1-8

Link W, Stelling D, Ebmeyer E (1994a) Yield stability in faba bean, Vicia faba L. 1. Variation among inbred lines. Plant Breed 112:24-29

Link W, Stelling D, Ebmeyer E (1994b) Factors determining the performance of synthetics in Vicia faba L. 1. Heterogeneity, heterozygosity, and degree of cross fertilization. Euphytica 75:77-84

Rust, Insa I (2006) Amendment of the "German land appraisal" (Reichsbodenschätzung) in consideration of climatic conditions. $\mathrm{PhD}$ thesis, University of Göttingen, Germany [in
German]. Available at http://www.webdoc.sub.gwdg. de/diss/2006/rust/

Schnell FW, Becker HC (1986) Yield and yield stability in a balanced system of widely differing population structures in Zea mays L. Plant Breed 97:30-38

Stelling D, Link W, Ebmeyer E (1994a) Yield stability in faba bean, Vicia faba L.2. Effect of heterozygosity and heterogeneity. Plant Breed 112:30-39

Stelling D, Link W, Ebmeyer E (1994b) Factors determining the performance of synthetics in Vicia faba L. 2. Syngeneration. Euphytica 75:85-93

Tigerstedt PMA (1994) Adaptation, variation and selection in marginal areas. Euphytica 77:171-174

Utz HF (1991) A computer program for statistical analysis of plant breeding experiments. Institute of Plant Breeding, Seed Science and Population Genetics. University of Hohenheim

Wolfe MS (1985) The current status and prospects of multilane cultivars and variety mixtures for disease resistance. Ann Rev Phytopathol 23:251-273

ZMP (Zentrale Markt- und Preisberichtstelle GmbH) (2004) http://www.zmp.de/. Cited Feb 2007 